\title{
MOVA-GUARULHOS: UM ESPAÇO DE MILITÂNCIA E O PERFIL DO SEU EDUCADOR
}

\section{Carlos Eduardo Sampaio Burgos Dias ${ }^{1}$}

Universidade de Campinas

\section{Patrícia Claudia da Costa ${ }^{2}$}

Universidade Federal de Viçosa

\section{Resumo}

Este artigo discutirá uma pesquisa quantitativa junto a 190 educadores do Programa Movimento de Alfabetização de Jovens e Adultos MOVA-Guarulhos, que buscou traçar um perfil do educador atuante neste movimento, contextualizando esse perfil com a própria história do MOVA em Guarulhos e na cidade de São Paulo. O instrumento de coleta consistiu num questionário com 42 questões que possibilitaram a caracterização do perfil nos seguintes aspectos: sociodemográfico, formação, trabalho, cultura, lazer e entretenimento e de atuação do educador alfabetizador. Conclui que a caracterização do perfil do educador como um militante depende de suas escolhas e ações, as quais determinam a percepção que o sujeito tem deste Movimento e de sua atuação.

Palavras-chave: MOVA-Guarulhos; Educador Popular; Militância.

1 Mestrando do Programa de Pós-Graduação em Educação da Unicamp. Historiador (UniABC) e Pedagogo (EFLCH/Unifesp) do Laboratório de História da Ciência do Instituto Butantã. carlinhosk3@yahoo.com.br

2 Patrícia Claudia da Costa. Doutoranda do Programa de Pós-Graduação em Educação da Faculdade de Educação da USP. Docente da Universidade Federal de Viçosa campus Florestal. patricia.claudia@ufv.br

Olh@res, Guarulhos, v. 1, n1, p. 477-499, maio. 2013. 


\title{
MOVA-GUARULHOS: an area of militancy and the profile of its educator
}

\begin{abstract}
This article presents a quantitative research about 190 educators of the Program Movement of Alphabetization of Young and Adults MOVA-Guarulhos. The research aimed to design a profile of educator who acts in this Movement, contextualizing that profile with the history of MOVA in the cities of Guarulhos and Sao Paulo. A questionnaire with 42 questions were used do collect data for characterizing the profile in the following aspects: sociodemographic, formation, work, culture, entertainment and action in alphabetization. It concludes that characterizing of profile of educator as a militant depends on the choices and actions that determine the perception of the subject about this Movement and its action.
\end{abstract}

Keywords: MOVA-Guarulhos; Popular Educator; Militancy.

Olh@ res, Guarulhos, v. 1, n1, p. 477-499, maio. 2013. 


\section{Introduç̧̃̃o}

Este trabalho apresentará uma breve retrospectiva da criação do Programa MOVA, como movimento social de alfabetização na cidade de São Paulo e como uma forma de indução de mobilização social no município de Guarulhos. No desenvolvimento do trabalho discutiremos a organização do Programa a partir da ideia de sociedade civil organizada, que, no caso do MOVA, constitui-se como um movimento social composto por diversas entidades.

Na sequência, comentaremos uma pesquisa realizada no ano de 2008, junto aos educadores do MOVA-Guarulhos, elaborada e aplicada por estudantes ${ }^{1}$ do curso de Pedagogia e demais licenciaturas da Unifesp, do então Campus Guarulhos, hoje, Escola de Filosofia, Letras e Ciências Humanas. Essa pesquisa foi objeto de avaliação das disciplinas de Práticas Pedagógicas Programadas II e III do curso de Pedagogia, correspondentes ao $2^{\circ}$ semestre de 2008, elaboração e aplicação, e $1^{\text {o }}$ semestre de 2009, tabulação e análise, e constitui-se num importante material para pesquisas e reflexão do próprio movimento. Neste trabalho, a análise da pesquisa foi dividida nos seguintes aspectos: sociodemográficos, formação, trabalho, cultura, lazer, entretenimento e de atuação do educador alfabetizador.

Em que pese o fato de os dados aqui apresentados terem sido coletados em 2008 e, portanto, serem passíveis de controvérsias quanto à sua validade para a compreensão do MOVA-Guarulhos nos dias de hoje, ao menos dois fatores validam a importância da reflexão proposta. Primeiramente, a própria coordenação do Programa atesta que nunca houve outra iniciativa de coleta de dados que permitisse uma identificação tão detalhada do perfil do sujeito que atua nesse movimento. O esforço empreendido pelos estudantes mencionados na terceira nota deste texto, em parceria com membros da coordenação pedagógica do Programa e orientado por professores da Unifesp $^{2}$, tornou possível que trouxéssemos ao conhecimento da comuni-

\footnotetext{
${ }^{1}$ Estudantes que contribuíram com a elaboração, aplicação e análise da pesquisa: Carlos Eduardo Sampaio Burgos Dias, Tatiane Sena, Fabiana de Lourdes Scarpim, Gleice Fonseca, Lucia Alves, Leandro Cescon, Bruno Roiz, Cássia Peres, Lays Pereira, Paula Franco, Caio Rosa, Danielle Regina, Vanessa Filgueira Santos, Daniel Dallaqua e Thiago Fijos de Souza.

${ }^{2}$ Foram os professores: Claudia Barcelos, Claudia Lemos Vóvio, Antonio Carlos Pinheiro e Márcia Romero.
}

Olh@ res, Guarulhos, v. 1, n1, p. 477-499, maio. 2013. 
dade acadêmica e demais interessados no tema, todas as essas informações que carregam consigo alto potencial de reutilização em outros estudos, tal como já foi feito por Dias (2011).

Em segundo lugar, publicizar os dados por meio de um artigo, cujo acesso é mais facilitado que uma monografia de conclusão de curso. No ano em que o MOVA- Guarulhos completa 11 anos de existência, é uma maneira de celebrar a primeira década do programa e, ao mesmo tempo, colaborar com a formação dos educadores, na medida em que a leitura deste texto pode vir a ser uma estratégia formativa dos próprios atores que permitiram sua realização.

\section{Relembrando a criação do MOVA e do MOVA-Guarulhos}

O MOVA - Movimento de Alfabetização de Jovens e Adultos - surgiu em 1989, com Paulo Freire à frente da Secretaria de Educação do Município de São Paulo. Sua ideia foi organizar em um movimento diversos núcleos e salas de alfabetização que já existiam na cidade e que careciam de uma política pública para sua fomentação. (...) centenas de núcleos de alfabetização de jovens e adultos, cada um com sua trajetória, que estavam sedentos de uma ação por parte do governo (BORGES, 2004).

Esse movimento se caracterizou pela parceria entre o Estado e organizações da sociedade civil, cujo intuito não era ser mais um programa de alfabetização de jovens e adultos, e sim um movimento capaz de aglutinar, em torno da alfabetização, sujeitos historicamente excluídos, e, a partir dela, refletir de modo a tornar seus sujeitos emancipados politicamente, capazes de ler o mundo criticamente. Santos (2004) anuncia uma caracterização muito peculiar, para além da decifração do código linguístico e da lógica matemática, o MOVA objetiva despertar o sentimento de consciência de grupo, através das relações sociais (...) questionando as desigualdades sociais.

Os grupos que o integram caracterizam-se, por sua vez, pelo acúmulo de vários estigmas: pobre, migrante, idoso, morador de periferia, entre outros (COSTA, 2008); o que exige uma compreensão do processo de alfabeti-

Olh@ res, Guarulhos, v. 1, n1, p. 477-499, maio. 2013. 
zação que leve em conta as especificidades da construção do conhecimento sobre a escrita e outros saberes numa sociedade letrada (TFOUNI, 1988, 2004) e grafocêntrica (GNERRE, 2003). Nesse contexto, o MOVA busca a superação da condição de analfabetismo numa sociedade em que a proficiência na leitura e na escrita é determinante para a definição do lugar ocupado no mundo do trabalho, bem como para o acesso à informação e aos bens culturais de maior prestígio.

No município de Guarulhos, o MOVA foi criado no ano de 2002, por meio do decreto 21.544, de 14 de março. Sua regulamentação veio através da portaria 4/2002-SE, de 22 de abril do mesmo ano. Assim como em São Paulo, sua organização se deu a partir da cooperação entre sociedade civil e Prefeitura, formalizada por meio de convênio junto à Secretaria Municipal de Educação (SME). No entanto, o contexto histórico era diferenciado. Se em 1989 havíamos acabado de sair da ditadura militar e assistíamos ao nascimento de uma nova Constituição Federal, em 2002, já vivíamos o transcorrer de um novo tempo democrático e, em Guarulhos, os movimentos sociais não estavam tão organizados quanto em São Paulo. Borges (2004) defende que os MOVAs, criados em diversas partes do país, inspirados no MOVA de 1989, tiveram outro ponto de partida, sendo o poder público o grande impulsionador, responsável por chamar a sociedade civil a compartilhar desse movimento ${ }^{3}$.

É importante destacar que a experiência com o MOVA em São Paulo foi possível graças à eleição de Luiza Erundina, então no Partido dos Trabalhadores (PT), para prefeitura da cidade, e que o MOVA, por muito tempo, foi identificado como sendo um programa vinculado às políticas de governo desse partido. Nesse sentido, o espaço para criação do MOVA em Guarulhos foi oportunizado a partir da primeira gestão do PT na cidade e a parceria tem se mantido ao longo de três gestões consecutivas. Atualmente,

\footnotetext{
${ }^{3}$ Em Guarulhos, assim como em outros municípios, foi um decreto o desencadeador do MOVA como um Programa que compõe a política pública de Educação. No transcurso entre a submissão e a aprovação deste artigo, o Programa Movimento de Alfabetização de Jovens e Adultos de Guarulhos - MOVA passa a ser instituído pela Lei 7.113, de 07 de janeiro de 2013. A influência de tais dispositivos legais na configuração da parceria entre a sociedade civil e o poder público municipal será objeto de nosso próximo estudo, que visará compreender o caráter de movimento social do MOVA e sua autonomia perante o Estado.
}

Olh@res, Guarulhos, v. 1, n1, p. 477-499, maio. 2013. 
essa vinculação partidária não é mais uma marca do Programa MOVA em âmbito nacional, que tem como uma de suas bandeiras de luta a manutenção da parceria com o poder público independentemente das mudanças de gestão, o que tem se efetivado em algumas localidades. Desse modo, novos sujeitos coletivos - leia-se partidos políticos - tem sustentado a existência do Programa, diluindo progressivamente a relação entre a proposta original do Movimento e o conteúdo programático do partido político no seio do qual ele foi criado, tornando o MOVA, a nosso ver, uma alternativa de barateamento da oferta de Educação de Jovens e Adultos (EJA) com consequente comprometimento de sua qualidade e continuidade, na medida em que:

A defesa de tese do MOVA como política pública vem carregada de ambiguidades. Se os governos assumirem o MOVA como política de governo, o MOVA perde seu caráter de movimento social, que é permanente, e se transforma num programa efêmero de um governo (GADOTTI, 2008, p.101).

Assim, o MOVA que se originou nos princípios da educação popular, vem demonstrando características de programas de superação do analfabetismo voltados apenas para as "técnicas" de alfabetização, como muitos outros na história do país, e vem perdendo, características de movimento social até então intrínsecas à sua proposta original, de constituir-se como movimento social e não como política pública (SANTOS, 2004; GADOTTI, 2008). Ao longo de sua história, é possível perceber diferentes entendimentos a respeito da função social atribuída ao Movimento de Alfabetização por seus principais agentes, os educadores, implicando assim os resultados alcançados.

\section{A organização do MOVA}

As parcerias entre as entidades da sociedade civil e a Prefeitura se dão por meio de convênios. A Prefeitura oferece orientação pedagógica aos educadores e uma ajuda de custo à entidade, que a repassa aos educadores e aos agentes populares, além de utilizar uma parte desse auxílio financeiro para custeio de materiais de consumo para as salas de aula. Em contrapar-

Olh@res, Guarulhos, v. 1, n1, p. 477-499, maio. 2013. 
tida, as entidades ajudam na mobilização dos educandos e, algumas vezes, disponibilizam salas para os educadores.

Segundo Salomón (2006), sociedade civil pode ser definida como o conjunto de organizações diversas que se mantêm independentes do Estado, com o qual se resgata o conceito residual de que sociedade civil é tudo que não é Estado. Gohn (2004) trabalha com a mudança de significado do termo sociedade civil nas últimas décadas, afirmando que entre os anos 1960 a 1980 o termo era sinônimo de tudo aquilo que não fosse militar. Já na década seguinte, com a ascensão do neoliberalismo, o termo fazia referencia a tudo que não fosse empresarial, e que no novo século, o termo está associado às ONGs (Organizações Não Governamentais).

Essa mudança de significados atribuída à sociedade civil também impactou diretamente nas ações de seus mobilizadores, principalmente de seus militantes:

Criou-se uma nova gramática na qual mobilizar deixou de ser para o desenvolvimento de uma consciência crítica ou para protestar nas ruas. Mobilizar passou a ser sinônimo de arregimentar e organizar a população para participar de programas e projetos sociais, a maioria dos quais já vinha totalmente pronta e atendia a pequenas parcelas da população. $\mathrm{O}$ militante foi se transformando no ativista organizador das clientelas usuárias dos serviços sociais (GOHN, 2004, p.26).

O MOVA criado em 1989 trabalhava com uma concepção de transformação da sociedade, de emancipação de seus sujeitos, bem como tinha em seus educadores, os militantes, os grandes mediadores dessa transformação.

(...) o educador popular é um militante que transcende a luta pela alfabetização, ele luta por causas sociais e faz da alfabetização sua ferramenta de luta. Já um ativista pode lutar perspicazmente pela causa da alfabetização, por exemplo, mas atua apenas como alfabetizador, como um técnico, sem a visão do todo, sem o caráter emancipatório e de transformação dos movimentos sociais, tornando a atividade de alfabetização um ato mecânico e não político (DIAS, 2011, p.21).

A partir dos dados obtidos na pesquisa realizada em 2008, junto aos educadores do MOVA-Guarulhos, discutiremos aqui as possibilidades de esses educadores atuarem na perspectiva da militância, junto à educação de milhares de jovens, adultos e idosos excluídos da escola, e que procuram no MOVA um acesso à educação capaz de melhorar suas condições de vida.

Olh@ res, Guarulhos, v. 1, n1, p. 477-499, maio. 2013. 
Dias (2011) discute se o MOVA-Guarulhos é considerado educação formal ou não formal, e constata que esse modelo de educação trabalha de forma híbrida, na medida em que a função social que este cumpre junto aos seus sujeitos acaba por caracterizar sua definição. Se para alguns, o MOVA é um programa da Prefeitura de Guarulhos que busca apenas superar o analfabetismo e incluir seus educandos na escola, para outros, o MOVA se caracteriza como um movimento social, que busca não apenas alfabetizar seus sujeitos, mas sim torná-los emancipados, críticos, capazes de intervir na sociedade propondo transformações, superando, portanto, seu histórico de exclusão.

A concepção do MOVA como um sistema híbrido ajuda a contextualizá-lo junto aos educadores para compreendê-los como militantes ou ativistas. Mas, o entendimento da função social do MOVA por seus educadores é o que realmente determina seu trabalho conforme uma dessas categorias.

\section{A pesquisa}

A pesquisa ${ }^{4}$ foi organizada pors estudantes da Unidade Curricular de Prática Pedagógica Programada - EJA ( $2^{\circ}$ semestre de 2008) do curso de Pedagogia da Unifesp, e pelo Grupo de Estudos em Educação de Jovens e Adultos da Unifesp, e teve como intuito traçar um perfil dos educadores do MOVAGuarulhos. Para isso foi aplicado um questionário no segundo semestre de 2008, com 42 questões, junto a 190 dos $304^{5}$ educadores à época. A aplicação do questionário foi feita junto a nove das onze turmas de formação permanente. Suas questões estavam divididas em três grandes eixos estruturantes: aspectos sócio demográficos, aspectos de formação e trabalho e práticas culturais, aqui reagrupadas nos seguintes eixos:

\footnotetext{
${ }^{4}$ A pesquisa completa pode ser encontrada em Dias, 2001, p.47-72.

${ }^{5} \mathrm{Na}$ época do início da pesquisa eram 304 o número de educadores, de acordo com os dados fornecidos pela Coordenação do MOVA em 2012, o ano de 2008 fechou com 306 educadores. Ver Quadro 1 (p. 8).
}

Olh@ res, Guarulhos, v. 1, n1, p. 477-499, maio. 2013. 


\section{Aspectos sociodemográficos}

Os números apresentados pela pesquisa apontam para o seguinte perfil de educador: mulher (89\%), adulta (64\% entre 26 e 45 anos de idade), brasileira (100\%), casada (64\%), com ao menos um filho $(81 \%)$, cristã (71\%) e residente no município de Guarulhos há pelo menos 10 anos (85\%). Esse perfil sociodemográfico não ignora os demais sujeitos do MOVA, tampouco imprime a estes educadores uma característica de homogeneidade. No entanto, ajuda a coordenação do MOVA na organização das formações permanentes e auxilia a Prefeitura na proposição de políticas públicas.

\section{Aspectos da Formação}

O eixo original da pesquisa, organizado em formação e trabalho, aqui será dividido em dois eixos, cada um deles tratado como um campo específico. No eixo de formação abordaremos a formação ${ }^{6}$ inicial desses educadores e no eixo trabalho serão abordados aspectos referentes ao MOVA enquanto experiência vinculada às atividades de militância ou ativismo, assim como de geração de renda, o que tem sido chamado por alguns, inclusive, de experiência profissional.

Segundo a pesquisa, $99 \%$ dos educadores concluíram o Ensino Fundamental. Vale lembrar que um dos critérios para ser educador do MOVA-Guarulhos é ter concluído o Ensino Médio ou ter três anos de experiência como educador em outro programa de alfabetização de adultos. Dos entrevistados, 98\% afirmaram ter concluído o Ensino Médio. Em paralelo ao Ensino Médio, 30\% destes também cursaram o Magistério, e

\footnotetext{
${ }^{6}$ Por formação inicial entendemos os percursos formativos, em nível de Educação Básica ou Superior, traçados pelo sujeito antes ou durante sua atuação no MOVA. O termo aqui não se refere à parte da formação oferecida pela Secretaria Municipal de Educação (SME) com o nome de "Formação Inicial dos Educadores do MOVA". Já a formação permanente aqui referida coincide com o nome adotado para a ação promovida pela SME em encontros quinzenais. Esse tipo de formação não foi objeto específico da pesquisa, embora tenha dado suporte a ela, pois o questionário foi aplicado durante as reuniões de formação permanente. Entretanto, foi possível perceber, através dos demais eixos da pesquisa, que o trabalho de formação permanente surte resultados positivos na medida em que inspira as práticas desenvolvidas junto aos educandos e as práticas culturais dos educadores que foram refletidas nos demais aspectos abordados na pesquisa.
}

Olh@res, Guarulhos, v. 1, n1, p. 477-499, maio. 2013. 
desses que cursaram apenas 5\% não concluíram. Uma nota importante é que 95\% dos educadores que cursaram o Ensino Fundamental e $93 \%$ dos que cursaram Ensino Médio o fizeram em escolas públicas. Além disso, dos $30 \%$ que cursaram o Magistério, $82 \%$ deles também o fizeram em escolas públicas. Nesse sentido, podemos constatar que a maioria dos educadores do MOVA-Guarulhos é egressa da escola pública.

Desses educadores, cerca de $40 \%$ iniciou uma graduação em curso superior, no entanto, menos da metade conseguiu concluir o curso. Destes que iniciaram a graduação em nível superior o fizeram maciçamente em instituições particulares (96\%). Isso evidencia uma das marcas da perversidade do sistema educacional brasileiro: o grande contingente de egressos da escola pública que acessam o nível superior por meio de instituições privadas.

Apenas 2,5\% do total de educadores iniciou um curso de especialização, sendo que apenas $1,1 \%$ desse total conseguiu concluir o curso, o que corresponde a apenas dois educadores.

De acordo com a pesquisa, metade dos educadores não assinalou o curso de graduação, porém, entre os assinalados $42 \%$ frequentaram cursos de licenciatura, sendo 19\% destes em cursos de Pedagogia. Porém, desses, a maioria (64\%) não teve nenhuma disciplina voltada à EJA (Educação de Jovens e Adultos) durante a graduação.

Nesse eixo, o perfil de educador apontado pela pesquisa foi de um sujeito com Ensino Médio concluído em escola pública. Parte significativa destes, $40 \%$, tendo iniciado a graduação em nível superior, porém, em instituições privadas.

\section{Aspectos de Trabalho}

Neste eixo apresentaremos as questões relacionadas às experiências em Alfabetização e ao MOVA enquanto um campo de trabalho. Dos 190 educadores pesquisados, 40 (21\%) deles estavam no MOVA há menos de 1 ano; 88 (46\%) deles estavam no MOVA entre 2 e 4 anos; e 62 (33\%) atuavam há mais de 4 anos. Se considerarmos a data da pesquisa, 2008, e o

Olh@ res, Guarulhos, v. 1, n1, p. 477-499, maio. 2013. 
ano de criação do MOVA em Guarulhos, 2002, podemos compreender que a maior parte deles se juntou ao movimento nos anos seguintes a sua criação, permitindo desse modo concluirmos que o movimento expandiu desde 2002, crescendo também o número de salas e de educandos atendidos, conforme quadro 1. No entanto, durante as reuniões de formação permanente era possível perceber certa rotatividade dos educadores.

Quadro 1 - As salas e educandos do MOVA-Guarulhos entre 2004-2012

\begin{tabular}{|c|c|c|c|c|c|}
\hline & 2004 & 2006 & 2008 & 2010 & 2012 \\
\hline Salas & 179 & 206 & 306 & 346 & 318 \\
\hline Educandos & 3508 & 4105 & 4258 & 5410 & 5000 \\
\hline Educandos/sala & 19,60 & 19,93 & 13,91 & 15,63 & 15,72 \\
\hline
\end{tabular}

Fonte: Dados informados pela Coordenação do MOVA-Guarulhos/SME.

A maioria desses educadores (72\%) não tinha experiência em nenhum outro programa de alfabetização, e dos que declaram alguma experiência, $16 \%$ foi no "Mobral" e 30\% no "Educar para mudar", destes, sendo 69\% em Guarulhos.

Entre os que já possuíam experiência em outro programa de alfabetização (38\%), a maioria (69\%) tinha até três anos de experiência.

Um quarto dos educadores entrevistados atua em outras redes de ensino regular, sendo $60 \%$ no ensino público estadual, $18 \%$ no ensino particular, $10 \%$ no ensino público municipal e $12 \%$ em outros tipos de ensino. Uma reflexão apontada no relatório de pesquisa foi de que esse dado não distinguiu em que nível ou modalidade de ensino esses educadores atuam: infantil, fundamental, médio, EJA ou superior. Não sendo possível, portanto, inferir as prováveis interfaces entre o trabalho realizado na prática profissional e a atuação no movimento.

Quando os educadores foram perguntados por que estavam lecionando no MOVA, as respostas foram: para 50\% deles, atuam "por opção, gosto e identificação com o MOVA e com os educandos jovens e adultos"; $29 \%$ afirmaram "pela relação com a comunidade local”; outros 13\% afirmaram ser "pela remuneração"; 4\% "pela falta de oportunidade no ensino regular"; e outros $4 \%$ possuíam outros motivos.

No que diz respeito à importância da ajuda de custo na composição da renda mensal, 33\% dos educadores afirmaram têm o MOVA como sua única fonte

Olh@res, Guarulhos, v. 1, n1, p. 477-499, maio. 2013. 
de renda; outros $15 \%$ como a principal fonte de renda; $23 \%$ declararam ser equivalente a aproximadamente metade da renda mensal; $12 \%$ afirmaram não representar muito em sua renda; e 5\% não responderam essa questão. Traçando um perfil neste eixo, podemos identificar um educador que se incorporou ao MOVA com, no máximo, quatro anos de pertencimento (67\%), sem experiência em outros programas de alfabetização (72\%). Atua majoritariamente $(79 \%)$ por gosto e identificação com o MOVA e pela relação com sua comunidade, sendo que metade da sua renda mensal ou parte significativa, senão o todo, provem da ajuda de custo obtida pela participação no Programa (83\%).

Assim, ao analisarmos esse eixo, podemos notar que os educadores atuam por identificação ao projeto pedagógico do movimento ou por sua relação com a comunidade. No entanto, um considerável contingente destes sujeitos é dependente da ajuda de custo mensal subsidiada pela Prefeitura.

\section{Aspectos de Cultura, lazer e entretenimento}

Nesse eixo selecionamos as questões relacionadas ao cotidiano dos educadores e suas práticas culturais, de lazer e entretenimento.

Quando perguntada a frequência com que leem jornais ou revistas, quase metade (46\%) afirmou ler diariamente e apenas $15 \%$ afirmou dificilmente ler. Quando consultados em relação aos conteúdos preferencialmente lidos, muitas opções foram citadas, com maior destaque para revistas semanais como "Veja, Época e Isto é" (29\%) e revistas religiosas (17\%). Nesse sentido, foi possível diagnosticar que há uma prática de leitura no cotidiano desses educadores. Em outra questão referente à leitura, quando perguntados sobre quantos livros haviam lido nos últimos seis meses, apenas $4 \%$ afirmaram não haver lido nenhum livro. A maioria (58\%) afirmou ter lido entre um e três livros nesse período, aproximadamente um quarto deles (27\%) afirmaram ter lido entre quatro e seis livros, e $11 \%$ afirmaram ter lido mais de sete livros.

Curiosamente, os participantes da pesquisa informaram que grande parte dos livros lidos havia sido sugerida pela Coordenação do MOVA: 69\%

Olh@ res, Guarulhos, v. 1, n1, p. 477-499, maio. 2013. 
afirmaram ter lido entre um e três livros sugeridos e $14 \%$ entre quatro e seis livros sugeridos. Apenas $17 \%$ do total de livros lidos não foram sugeridos pela Coordenação do MOVA. Observamos que a maioria leu livros nos seis meses anteriores à pesquisa e os dados sugerem que os livros lidos, apesar de indicados, podem ter sido encarados como leituras obrigatórias das formações permanentes.

Se por um lado isso pode ser um passo para que a leitura de livros seja naturalizada, por outro, podemos perceber que este ainda não parece ser um hábito intrínseco aos educadores do MOVA-Guarulhos, o que põe em xeque o status de leitor consolidado. Para confirmar essa hipótese, pedimos em outra questão que anotassem os livros e autores que mais tinham gostado, e $33 \%$ deles se identificaram com Paulo Freire, 14\% com Cecília Meireles e $11 \%$ com Monteiro Lobato, todos estes autores tendo sido indicados pela Coordenação do Programa. Há de se destacar que os títulos lidos por sugestão da Coordenação foram distribuídos gratuitamente para todos os educadores e agentes populares nos anos de 2007 e 2008, como parte do projeto político-pedagógico de formação do movimento, deixando muito evidente que o acesso aos livros é um fator determinante na prática da leitura ${ }^{7}$.

Em outra questão tentamos identificar quais os hábitos mais comuns destes educadores, e perguntamos com qual frequência iam a determinados estabelecimentos ou instituições. Obtivemos um conjunto de respostas que evidenciam que a frequência a espaços culturais, tais como cinemas e teatros, não faz parte do cotidiano da maioria dos integrantes do MOVAGuarulhos. Entre os que declararam ir frequentemente a esses espaços, 5\% deles afirmaram ir ao cinema, 3\% ao teatro e 7\% a shows de música ou dança. No outro extremo da escala de frequência, 64\% declararam que raramente ou nunca vão ao cinema, $68 \%$ ao teatro e $60 \%$ a shows de música

\footnotetext{
${ }^{7}$ Os lidos distribuídos e estudados em 2007 foram Pedagogia da autonomia, de Paulo Freire e Paulo Freire para educadores, de Vera Barreto. Em 2008, a distribuição priorizou leituras de fruição com as obras: Quando o carteiro chegou - Monteiro Lobato, organizado por Rolf Mario Treuherz, Três Marias de Cecília, da própria Cecília Meireles e organizado por Marcos Antonio de Moraes e Este seu olhar, uma coletânea de relatos autobiográficos de escritores famosos, organizada por Regina Zilberman. Todos os livros são da Editora Moderna.
}

Olh@ res, Guarulhos, v. 1, n1, p. 477-499, maio. 2013. 
ou dança. Contudo, quando consultamos quantos ouviam noticiários no rádio, 59\% afirmaram ouvir com frequência e $27 \%$ ouvir às vezes. Quando consultados se ouviam outros programas de rádio, $41 \%$ afirmaram fazê-lo com frequência e 35\%, às vezes. Na questão referente à televisão, 66\% declararam assistir vídeos de filmes com frequência, e $26 \%$ afirmaram assistir às vezes. Em relação aos noticiários na televisão, $84 \%$ afirmaram assistir com frequência e $13 \%$ assistiam às vezes.

Com esses dados podemos perceber que o acesso aos bens culturais mais em voga na contemporaneidade acontece dentro de casa e implica em escassos investimentos. Há algumas pistas que justificam esse fato. A primeira diz respeito diretamente à facilidade do acesso aos vídeos, notícias e músicas em casa por meio de aparelhos como a televisão, o rádio, o computador (com acesso à internet), enfim, equipamentos cuja aquisição e manutenção tem se tornado cada vez mais acessiveis. Em segundo lugar, a falta de opções de espaços culturais formais nas proximidades, uma vez que a maioria dos sujeitos que responderam aos questionários vive na periferia da cidade, onde tradicionalmente há escassez desses espaços, e, mesmo entre aqueles que estão mais próximos dos bairros centrais, há de se considerar que o município de Guarulhos ainda carece de equipamentos públicos que promovam o acesso a bens culturais. Em terceiro lugar, o custo atribuído a essas atividades fora de casa é um elemento importante na definição de tais hábitos da população.

Questionados sobre a prática de visitação a espaços culturais formais, apenas 7\% afirmaram visitar museus com frequência. Porém, quando perguntamos quantos frequentam igrejas ou cultos religiosos, $62 \%$ afirmaram o fazer frequentemente.

Algumas hipóteses explicam essa diferença. Primeiramente, que as pessoas têm uma religião e faz parte de seus preceitos frequentar suas reuniões. Poderíamos até destacar que o número de igrejas é muito maior que o de museus, logo, o acesso seria mais fácil. Entretanto, a questão é mais complexa que a aparente diferença quantitativa de distribuição dos espaços - museu e igreja - na cidade e está intimamente ligada ao acesso.

Olh@ res, Guarulhos, v. 1, n1, p. 477-499, maio. 2013. 
A dificuldade de acesso ao museu não permite criar uma cultura de frequentadores de espaços culturais, uma vez que há poucas opções para tal e a formação de público, seja na igreja, no cinema ou no teatro está diretamente relacionada à presença desses equipamentos nas comunidades. O que queremos dizer é que, embora a frequência a igrejas e a museus sejam duas práticas culturais incomparáveis, a disparidade entre o número de espaços religiosos e de espaços museológicos numa cidade, assim como de outro espaço cultural qualquer, provoca nossa reflexão sobre os sentidos atribuídos, pelas comunidades e pelo poder público, aos espaços que merecem ser construídos, preservados e frequentados. Além disso, há de se problematizar também os sentidos e valores que tem sido atribuído a tais práticas culturais na formação, inclusive escolar, dos sujeitos.

Finalizando esse eixo, $21 \%$ dos educadores afirmaram não usar o computador; $29 \%$ utilizavam para atividades do próprio MOVA e apenas 9\% para entretenimento. Destes, $27 \%$ declararam usar o computador diariamente e $22 \%$ de uma a duas vezes por semana. Quando perguntados se enviam e recebem e-mail, praticamente metade (46\%) informou que utilizam tal tipo de comunicação.

Assim, desse bloco geral que fez um apanhado sobre os hábitos de cultura, entretenimento e lazer, podemos destacar que as opções oferecidas na região do bairro dos Pimentas, e na cidade de Guarulhos como um todo, ficam muito aquém das necessidades dos educadores do MOVA e faz-se necessário incentivar e cobrar políticas públicas de acesso a esses bens. Como também se faz necessário um trabalho de educação e valorização desses bens culturais junto às escolas, comunidades e famílias, tornando-os uma conquista efetiva e reconhecida.

O perfil de educador evidenciado nestas questões aponta para uma pessoa que lê frequentemente jornais e revistas, além disso, lê uma quantidade razoável de livros, mesmo que sugeridos, porém frequenta pouco o cinema, teatro, shows musicais, espetáculos de danças e museus, informando-se e entretendo-se com mais frequência pelas culturas radiofônicas e televisivas, uma vez que, nem mesmo o computador e a internet são bens acessíveis.

Olh@ res, Guarulhos, v. 1, n1, p. 477-499, maio. 2013. 


\section{Aspectos de atuação do educador alfabetizador}

Neste eixo separamos as questões relacionadas diretamente à atuação do educador junto à sua sala de MOVA. Quase a totalidade de educadores (94\%) afirmou estar preparada "para dar aulas no MOVA".

Quando consultados se sua sala participava de mostras e eventos organizados pela SME (Secretaria Municipal de Educação), 73\% afirmaram participar dessas atividades, o que demonstra que as ações do movimento de alfabetização não são isoladas das demais ações promovidas por aquela Secretaria e que a participação em tais eventos constitui uma forma de divulgação do trabalho realizado pelo Programa para os demais educadores da rede pública municipal, ao mesmo tempo em que os coloca em contato com as ações que acontecem nas escolas.

Em relação à preferência de materiais didáticos utilizados em sala de aula, a variedade de respostas foi grande, de modo a não existir uma preferência: $23 \%$ afirmaram usar livros diversos; 20\% usavam revistas; $18 \%$, jornais; 16\%, materiais cedidos pela Prefeitura de Guarulhos; $10 \%$ afirmaram usar livros didáticos; e 13\% utilizavam outros materiais. Quando perguntados qual o assunto mais trabalhado em sala, também houve uma diversidade de respostas, entre as quais destacamos as de maior ocorrência de conteúdos informados: $23 \%$ de conteúdos de educação; outros $23 \%$ de meio ambiente; $18 \%$ de política; $18 \%$ saúde; $10 \%$ de saúde pública; e $6 \%$ com outros conteúdos. A grande diversidade de materiais e de temas trabalhados é mostra de que o MOVA-Guarulhos desenvolve-se sem a preocupação de construir uma unidade de conteúdos programáticos e metodológicos, restando a cada educador a autonomia de decidir sobre os elementos concretos de execução do trabalho em sua sala de aula.

Quando consultados se seus educandos participavam da elaboração das aulas, 62\% dos educadores afirmaram que sim, 30\% responderam negativamente e $8 \%$ não souberam responder. Com relação à participação da sala de MOVA em atividades fora do próprio MOVA, 23\% dos educadores responderam não participar; $17 \%$ frequentavam teatros e cine-

Olh@ res, Guarulhos, v. 1, n1, p. 477-499, maio. 2013. 
mas; $20 \%$ frequentavam festas; $13 \%$ participavam de encontros religiosos; $16 \%$ visitavam exposições e $11 \%$ outros espaços.

Até aqui o que podemos constatar é que a maioria dos educadores participa das mostras e eventos promovidos pela Prefeitura de Guarulhos. Em relação aos materiais e assuntos abordados em sala de aula, verifica-se uma heterogeneidade de respostas. Além disso, constatamos que a maioria dos educadores abre suas aulas para a participação de seus educandos, embora não tenha sido explicitado como essa participação acontece, e que a maioria participa de atividades fora do MOVA, demonstrando haver uma relação de comunidade além do ofício de ensinar e aprender a ler e escrever. Curiosamente o percentual de frequência das turmas de alfabetização a teatros e museus $(17 \%)$ é superior ao percentual obtido no eixo que investigou a frequência dos educadores a esses mesmos espaços (8\%). A aparente inconsistência desses dados oculta uma faceta da realidade do movimento: a valorização de algumas vivências culturais como prática educativa impulsiona educadores e educandos para experimentar algo inédito ou pouco frequente para ambos. A visita a exposições, teatros e museus é uma mostra disso, ou seja, há uma significativa parcela de educadores que tem acesso a esses espaços apenas na condição de responsáveis por uma turma de educandos em atividades promovidas como parte de um projeto da entidade ou por iniciativa do próprio educador ou do agente popular.

No que diz respeito ao vínculo dos educadores com a comunidade e sua sala de MOVA, $48 \%$ afirmaram residir na região, $19 \%$ trabalhavam no entorno e $13 \%$ informaram ter ali familiares. Percebemos, então, que a maior parte deles possui algum tipo de vínculo com a comunidade em que estão inseridos, e isto é um principio básico na escolha do educador, o conhecimento dos seus educandos, de seus modos de viver.

Por fim, 69\% dos educadores afirmaram participar de algum tipo de organização social. Sendo que 33\% afirmaram participar de Associações Religiosas, 24\% de Associações de Moradores, 18\% de Organizações Não Governamentais, $17 \%$ de Grupos ligados ao atendimento de crianças e jovens, $6 \%$ de Partidos Políticos e 2\% de outras instituições.

Olh@ res, Guarulhos, v. 1, n1, p. 477-499, maio. 2013. 
Concluindo esse eixo, podemos notar que os educadores possuíam forte vínculo com sua comunidade, participando e interagindo com ela a partir das salas do MOVA e atuando em diversas organizações sociais. Embora os dados apresentados no Aspecto Formação revelem que a maior parte dos sujeitos não teve acesso à formação para docência, trata-se de um grupo que se demonstra preparado para tal exercício.

\section{Considerações Finais}

Os dados apresentados nos permitem afirmar que a análise do perfil do educador do MOVA-Guarulhos, como um militante ou ativista, demanda maior aprofundamento no que diz respeito à figura de educador popular e à sua trajetória formativa.

A ideia de que os movimentos sociais de educação popular utilizam a alfabetização como um instrumento político de emancipação das classes populares é lugar comum nos discursos dos mais distintos sujeitos que tomam parte da ação. Desde os fundamentos teóricos proferidos por Paulo Freire, referência primordial da educação popular, que assevera:

Inicialmente me parece interessante reafirmar que sempre vi a alfabetização de adultos como um ato político e um ato de conhecimento, por isso mesmo, como um ato criador. Para mim seria impossível engajar-me num trabalho de memorização mecânica dos ba-be-bi-bo-bu, dos la-le-li-lo-lu. Daí que também não pudesse reduzir a alfabetização ao ensino puro da palavra, das sílabas ou das letras. Ensino em cujo processo o alfabetizador fosse "enchendo" com suas palavras as cabeças supostamente "vazias" dos alfabetizandos. Pelo contrário, enquanto ato de conhecimento e ato criador, o processo da alfabetização tem, no alfabetizando, o seu sujeito. (FREIRE, 1989, p.13).

Até os documentos legais que regulamentam o funcionamento do Programa, tal como a Portaria 4/2002-SE que estabelece como objetivos do MOVAGuarulhos:

\footnotetext{
- Propiciar a jovens e adultos analfabetos o acesso à escolarização, capaz de permitir o domínio da leitura e da escrita, assim como outros conhecimentos pertinentes ao desenvolvimento global do educando, de forma a viabilizar o prosseguimento dos estudos, numa perspectiva de aquisição da cidadania e do desenvolvimento da consciência crítica do educando. $[. .$.

- Desenvolver uma metodologia de Educação de Jovens e Adultos que leve em consideração as reais necessidades do aluno, partindo da realidade deste e respeitando seu processo de conhecimento; não se reduzindo, portanto, a uma reposição de escolaridade ou a uma educação compensatória. (GUARULHOS, 2002, p.2. Grifos nossos).
}

Olh@res, Guarulhos, v. 1, n1, p. 477-499, maio. 2013. 
A partir de tais ideias, consubstanciadas no esforço de promover "o desenvolvimento da consciência crítica do educando" por meio de uma educação popular que supere a lógica da suplência, o MOVA-Guarulhos vem se constituindo. A lógica da suplência, ainda presente em ações voltadas para a elevação de escolaridade de jovens e adultos, inspira ações cada vez mais rápidas, com menor custo e maior rendimento, ou seja, certificação em tempo bem reduzido para "suprir o tempo perdido", mesmo que isso custe um aprendizado precário ou desvinculado dos interesses do sujeito. Em seu lugar, o Programa MOVA-Guarulhos tem tentado construir uma ação educativa que respeite o processo de conhecimento dos alfabetizandos, especialmente quanto aos tempos e ritmos de aprendizagem e aos conteúdos de interesse da comunidade, metodologicamente tratados pelo uso de temas geradores como norteadores dos planejamentos de aula. Assim, a atuação do educador como militante é essencial no ato de alfabetização como instrumento político de transformação social. E, por meio dos dados obtidos por esta pesquisa podemos afirmar que esse educador tem um envolvimento com sua comunidade, seja morando ou trabalhando. Além disso, a maioria participa de organizações sociais, entidades e/ou instituições em sua comunidade. A falta de equipamentos públicos de fins culturais pode ser um obstáculo tanto para a formação desse educador quanto no trabalho de transformação junto aos educandos. No entanto, essa escassez de equipamentos poderia ser uma pauta mobilizadora do MOVA-Guarulhos como movimento social.

Porém, o que identifica sua atuação como militante ou ativista é a concepção que esse educador tem do MOVA-GUARULHOS. Nesse sentido, esse educador precisa ter clareza quanto à função social desse movimento. Somente pertencer à comunidade e ser um bom alfabetizador não faz desse educador um militante, ainda que sejam fatores primordiais na construção de um movimento social de alfabetização.

\footnotetext{
A consciência de classe dos sujeitos que compõem o movimento, expressa na coerência de suas ações pela construção de uma sociedade mais igualitária, deveria ser o elemento mais revelador da natureza de movimento social deste programa de alfabetização, independentemente da gestão que lhe ofereça ou the negue parceria (DIAS, 2011, 42-43).
}

Olh@ res, Guarulhos, v. 1, n1, p. 477-499, maio. 2013. 
O que pode caracterizar o MOVA e seus educadores como militantes ou ativistas são suas ações dentro do movimento, e sua percepção desse movimento, sua função social, singularidades que fundam sua natureza e sentido. Todavia, os dados obtidos a respeito da ajuda de custo podem apontar para educadores que atuem como ativistas da alfabetização, tendo no MOVA uma possibilidade de inserção no mundo do trabalho, e não um espaço de militância, consagrando a lógica neoliberal de desresponsabilização do Estado, que transfere para a sociedade sua responsabilidade, no caso, a educação. "Porém, mais importante do que a prefeitura reconhecer o MOVA como movimento social é o próprio movimento se reconhecer como tal" (Dias, 2011, p.40). Quanto a isso concordamos com Gohn ao afirmar que:

A participação da sociedade civil nas novas esferas públicas - via conselhos e outras formas institucionalizadoras - também comporta uma premissa básica: seu objetivo não é substituir o Estado, mas lutar para que este cumpra seu dever de propiciar educação de e com qualidade para todos (GOHN, 2010, p.64).

O MOVA como uma política pública de superação do analfabetismo não extingue necessariamente o seu caráter de movimento social. O que há de se investigar, a partir dos dados aqui apresentados, é a reflexividade do educador do MOVA-Guarulhos a respeito das potencialidades do Programa no fomento da mobilização social que tem nele próprio um militante a ser revelado. Inerentemente a esse ponto de reflexão, há de se pensar também na autonomia do movimento e a sua relação com a autonomia dos sujeitos que o compõem.

Tem uma outra coisa, a autonomia dos movimentos. O Pedro Pontual fez a sua tese sobre o MOVA e a conclusão que ele tirou foi que os movimentos populares se constituíram num grande ator social, em São Paulo, a partir do MOVA. Quer dizer, uma outra qualidade de movimento, o MOVA fortaleceu 97 entidades que fizeram essa parceria (GADOTTI, 2004, p.25).

Finalizando, o que caracteriza o perfil do educador do MOVA-Guarulhos como um militante são suas escolhas e ações, as quais determinam a percepção que o sujeito tem desse movimento. A despeito da influência exercida pela formação oferecida pela SME, suspeitamos que a concepção de Movimento de Alfabetização seja fundamentalmente determinada pela própria atuação de cada sujeito no movimento. Sua trajetória de vida e a conjuntura aqui analisada fornecem subsídios para essa atuação.

Olh@ res, Guarulhos, v. 1, n1, p. 477-499, maio. 2013. 
Se encarado apenas como um programa voltado para a superação do analfabetismo ou como uma fonte de renda, teremos então um ativista; se percebido como um espaço de intervenção política para construção de uma sociedade que supere não só o analfabetismo, mas que perceba o vínculo deste com as desigualdades sociais, culturais e econômicas do País e busque superá-las num todo, podemos ter um militante.

Assim, o que podemos concluir das análises aqui realizadas é que os educadores podem ser considerados militantes. No entanto, a percepção de agente transformador da sociedade cabe aos próprios educadores assumir essa condição. E assumida essa condição de militante, com atuação política de suas entidades e organizações, identificando a função social do Programa MOVA como uma possibilidade de transformação da e na sociedade, aí sim, podemos pensar o MOVA-Guarulhos como movimento social. Logo, não existe movimento social, se não houver militância.

Olh@ res, Guarulhos, v. 1, n1, p. 477-499, maio. 2013. 


\section{Referências Bibliográficas}

BORGES, Liana. O papel do poder público e da sociedade civil. In: SANTOS, Maria Alice de Paula (Org.). MOVA em Movimento. Porto Alegre, RS: Ação Educativa; Instituto Paulo Freire; Secretaria de Estado de Educação-RS, 2004.

COSTA, Patrícia Claudia da. Sem medo de ser falante: conquistas da oralidade por educandas idosas do MOVA-Guarulhos. [Dissertação de Mestrado]. São Paulo: Faculdade de Educação da Universidade de São Paulo, 2008, 197pp.

DIAS, CESB. MOVA-Guarulhos: educação formal ou não-formal. [Trabalho de Conclusão de Curso]. Guarulhos (SP): Escola de Filosofia, Letras e Ciências Humanas da Universidade Federal de São Paulo, 2011. 72pp.

FREIRE, Paulo. A importância do ato de ler: em três artigos que se completam. $23^{\mathrm{a}}$ ed. São Paulo: Autores Associados: Cortez, 1989.

GADOTTI, Moacir. MOVA - parcerias e participação popular. In: SANTOS, Maria Alice de Paula (Org.). MOVA em Movimento. Porto Alegre, RS: Ação Educativa; Instituto Paulo Freire; Secretaria de Estado de Educação-RS, 2004.

GADOTTI, Moacir. MOVA, por um Brasil Alfabetizado. São Paulo: Instituto Paulo Freire, 2008.

GOHN, Maria da Glória. Empoderamento e participação da comunidade em políticas sociais. Saúde e Sociedade, v.13, n.2, p.20-31, maio-ago 2004.

GNERRE, Maurizio. Linguagem, escrita e poder. $4^{\text {a }}$ ed. São Paulo: Martins Fontes, 2003.

GOHN, Maria da Glória. Educação não-formal e o educador social: atuação no desenvolvimento de projetos sociais. São Paulo: Cortez, 2010

GUARULHOS. Decreto 21.544, de 14 de março de 2002. Dispõe sobre a instituição do programa denominado Movimento de Alfabetização de Jovens e Adultos de Guarulhos MOVA-GUARULHOS e dá outras providências. Diário Oficial do Município, Guarulhos, SP, 15 mar. 2002, p.02.

Lei 7.113, de 07 de janeiro de 2013. Institui o Programa Movimento de Alfabetização de Jovens e Adultos de Guarulhos - MOVA e dá outras providências. Diário Oficial do Município, Guarulhos, SP, 08 jan. 2013, p.02. 
SANTOS, Maria Alice de Paula (Org.) MOVA em Movimento. Porto Alegre, RS: Ação Educativa; Instituto Paulo Freire; Secretaria de Estado de Educação-RS, 2004.

SALOMÓN, Leticia. O Papel da Sociedade Civil na Construção da Democracia In: PONTUAL, Pedro, IRELAND, Timothy (Org.). Educação Popular na América Latina: diálogos e perspectivas. Brasília, DF: Ministério da Educação; UNESCO, 2006.

TFOUNI, Leda V. Adultos não alfabetizados: o avesso do avesso. Campinas: Pontes, 1988. Letramento e alfabetização. São Paulo: Cortez, 2004. 